\title{
Application of Health Detector
}

\author{
Ahmad Taqwa ${ }^{1}$ Ade Silvia Handayani ${ }^{1, *}$ Nyayu Latifah Husni ${ }^{1}$ Rahmat Budiarto ${ }^{2}$ \\ ${ }^{1}$ Department of Electrical Engineering, Politeknik Negeri Sriwijaya, Palembang, Indonesia \\ ${ }^{2}$ College of Computer Science and Information Technology, Albaha University, Saudi Arabia \\ *Corresponding author. Email: ade_silvia@polsri.ac.id
}

\begin{abstract}
Nowadays, Wireless Body Area Network has an important role in health care monitoring applications. This practical method offers more advantages in monitoring patient health care remotely in real-time, for example, increasing human discipline in health care, easy to operate, flexible, and able to reduce healthcare costs. This patient health care monitoring system was developed with advances from mobile devices and Cloud IoT to measure various physical parameters regarding patient health. Physical parameters measured are body temperature, blood pressure, heart rate, and blood oxygen levels by utilizing the performance of several worn medical sensors - patient's Electronic Blood Pressure Monitor. The information collected from these sensors will be processed by Arduino Mega to be forwarded to the Cloud Server using the ESP8266 Node MCU, which is connected to Wi-Fi. The information obtained will be displayed on the android application. Therefore, this tool is more efficient in health care based on mobile application services in real-time.
\end{abstract}

Keywords: Wireless Body Area Network, Cloud Computing, Healthcare, Internet of Things, Android Devices.

\section{INTRODUCTION}

Nowadays in modern society, most of the busyness of a series of tasks and jobs makes people forget some basic things in their daily lives, for example, the elderly and people who are victims of chronic diseases need to have their health checked regularly and appropriately time. [1].

Suppose people suffering from diseases are required to have their health conditions checked regularly and on time. In that case, technology in the health care monitoring system from anywhere and anytime becomes essential to improve the delivery of health care monitored by the medical team. It can facilitate two-way communication between the medical team, patients, and people who care for others, namely caregivers, to maximize efficiency in carrying out daily activities.

As a health-care monitoring system anywhere, this technology promises increased efficiency and accuracy in medical care availability due to recent advances in wireless and electronic communications offering smart wearable sensors in multiple domains. In this regard, Wireless Body Area Networks is an active area of research and development as they provide the potential for significant improvements in health care delivery and monitoring [2].

Wireless Body Area Networks play an important role in health care monitoring applications. This most practical method can provide a cost-effective tool for remote real-time monitoring of patient health-care [3]. WBAN for health care monitoring system has several sections that can be classified based on the interaction between the patient and the medical team in real-time. It namely the type of information transmitted such as text, audio, and video [4], regarding the entire medical circuit such as diagnosis of health conditions, treatment, and prevention of disease, as well as the provision of continuous health care services without any obstacles and disturbing the quality of life. It is possible to develop applications on intelligent devices in medical sensing and active and real-time communication in monitoring patients' health conditions to provide appointments of hospitals, caregivers, and medical teams.

Many health care monitoring applications on smart devices have proven their efficiency in enhancing and empowering WBANs in simplifying invasive devices to non-invasive by collecting physiological signals from worn medical sensors. This health care monitoring 
detects several varied health parameters, such as [5] implementing a blood pressure monitoring system using Bluetooth and Wi-Fi to access results on handheld devices such as cell phones, tabs, and laptops. So, concerned people can access the patient's blood pressure readings remotely. However, this monitoring system is less efficient because the data reading can only be accessed through the website page. Moreover, [6] activates medical sensors on the smart bracelet to help nurses and doctors monitor and track elderly health parameters in real-time. However, not all the elderly can run the electronic health care system properly, so this system becomes complicated for the elderly, and high costs make this system less efficient. This paper presents a health care monitoring system with important health parameters, namely body temperature, blood pressure, heart rate, and blood oxygen levels, based on Android by utilizing the Internet of Things (IoT) network and cloud computing. The manufacture of this tool provides a travel-friendly hardware system to overcome problems such as the distance of health checks, the level of human discipline, and the cost of meeting health care needs in real-time.

This health care monitoring system will help people monitor their health conditions to prevent and control their chronic diseases and allow the medical team to monitor and assist them when needed. This system will be helpful for professional medical teams in providing a good way of medical care for patients and providing follow-up actions for patients. Thus, it is possible to reduce the loss of life due to the work of this tool providing potentially beneficial health monitoring.

This monitoring system for health care is designed with heterogeneous sensors such as the MLX90614 sensor for monitoring body temperature, the Xgzb 040db $1 \mathrm{R}$ sensor for monitoring blood pressure, the MAX 30100 sensor for monitoring heart rate and blood oxygen levels. In addition, the Electronic Blood Pressure Monitor is used as a tool to determine the human heart rate and blood pressure. The data collected from several sensors will be processed by Arduino Mega to be forwarded to the Cloud Server using the ESP8266 NodeMCU connected to Wi-Fi. The information obtained will be displayed on the android application.

\section{ANDROID APPLICATION FOR HEALTH MONITORING}

Smartphones are an interesting and unique technology because of their rapidly increasing computing power. The computing power of smartphones is designed with smart sensors. They can capture speech characteristics, location, phone calls, text messages, or social media activity. Social media activity has advanced internet, storage, and data processing capabilities, allows timely creation of personal profiles and personalization, and alerts network user [7]. Sensors on this smartphone have been used in a variety of profitable applications, from car navigation to applications tailored to user needs.

Adults' ownership and use of a smartphone are close to the level of ownership and use of a desktop or laptop computer. Due to smartphone application services that offer great facilities and potential in real-time according to user needs. The use of applications on adult smartphones plays a role in various activities, such as healthcare services. Where [8] in emergencies from health conditions can form other domains so that mobile applications play an important role in expanding health care services on mobile devices, such as GPS units.

In recent years, advances in mobile device technology have received attention as a platform for extensive computing research. With advances in mobile technology [10], many health care centers are emerging and developing to improve health care services to optimize medical resources by investing in mobile information technology infrastructure. It aims to directly link hospitals, clinics, and health care organizations to enable the exchange of medical data [11]. In addition, research on adopting wearable, cellular technology in health care has been extensive. Many mobile applications in health care have been available and have a high buying and selling value. Existing mobile applications often focus on services to help people who have difficulty maintaining an independent life.

Modern breakthroughs with mobile application systems for health care are an important domain and have changed the ecosystem in health care. It refers to health care services and health information storage that were centered initially in hospitals. They are now patient-centered and have actively involved patients in the monitoring process to access their health information electronically via the internet and related technologies. The data structure that stores metadata for this information set allows the medical team to access health information without quickly asking the patient. Thus, the application system on mobile is better than the book and pen approach and can expand the health care service system with a new set of benefits for patients.

The mobile application's healthcare service system is functional as a monitor of vital signs in health services by detecting health and providing medical information in real-time [12]. For example [13], it presents a patient health monitoring system using an IoT platform to measure various physical parameters related to patient health such as temperature, blood pressure, pulse, glucose levels, and oxygen levels using worn sensors. It helps to get information about the patient's health in a short time. Meanwhile, [14] describes a system that regularly monitors and conforms to treatment and lifestyle changes to assess the quality of life of type 2 diabetes patients through a mobile application. This 
mobile application focused on lifestyle modification, and medication management was used for six months by 150 patients. The evidence generated in this study shows that this technological approach can be used as a public health benchmark to improve the quality of life of type 2 Diabetes Mellitus patients. Then, [15] a collaborative sensor network will then use a mobile application system to monitor the cardiorespiratory and daily physical activities of patients with chronic obstructive pulmonary disease. The system consists of several medical sensors connected wirelessly to a master device to acquire medical data in daily life or supervised medical examinations. Furthermore, [16] it also manages ischemic heart disease by utilizing a low-cost Android-based ECG monitoring system that allows ischemic patients to be monitored remotely by their physicians.

\section{COOPERATION BETWEEN IOT AND CLOUD FOR HEALTH MONITORING}

Internet of Things (IoT) is the future of the Internet and one of the most important technologies used today in all areas, where everything will be connected to the Internet [17]. IoT combines several things by utilizing the Internet as the foundation of a communication system to build intelligent interactions between users and the tasks at hand. Users can complete a series of tasks by involving smartphones in data processing, visualizing data for users, and sending data to other data centers. This communication system can operate in realtime 24/7 with the latest advances in Cloud computing technology.

Cloud, as a critical component of IoT, provides valuable application-specific services in the application domain. Several emerging IoT and cloud computing technologies take advantage of specific and tailored IoT-based services. Cloud IoT is popular in planning to solve several service domains such as application development, device management, system management, heterogeneity management, data management, tools for analysis, deployment, monitoring, visualization, and research [18]. This technology is a model that allows users to access the network comfortably and can be configured with resources such as networks, servers, storage, applications, and services that can be quickly provided and released to users. [19].

The increasing prevalence of modern information technology visible to users offers new opportunities by combining IoT and cloud computing. These two technologies rely on the sharing of processing assets between servers and applications that have evolved to facilitate and transfer information over the Internet. So that [20] increased performance in terms of resource utilization, storage, energy, and high computing capabilities and coverage to handle today's world that provides many new services dynamically and distributed.

New services that are dynamically distributed on IoT technology and Cloud computing have an important role in the constantly changing computing world, especially in monitoring service systems. In this case, the combination of IoT architecture and Cloud computing is often utilized to create a smart healthcare monitoring service system capable of supporting applications in real time while processing and executing data generated by the imposed sensor network. The collaboration of these two technologies allows smart devices to access health care information from various places.

Health-care monitoring service systems on smart devices that combine IoT technology and Cloud computing have been used progressively. The system monitors the patient's health condition and the accessibility of several records regarding the patient's medical care data effectively even in remote locations, reducing costs, and improving medical facilities. Therefore, a portable health monitoring application in real-time is critical because it can be a suitable means to minimize the distance between the patient and the medical team.

In general, Cloud IoT in a healthcare monitoring service system has four functional modules: data cleaning, data storage, data analysis, and disease warning [21]. It can provide high security to protect patient data. This system has significant potential for analyzing patient health care data to negate any adverse circumstances. The IoT framework works by collecting patient data using medical devices and sensors in healthcare monitoring services. Sensor data can be directly forwarded to the Cloud server, and authorized users can access the data with internet-enabled devices to avoid identity theft or clinical eVarious monitoring devices in healthcare service systems with the advancement of Cloud IoT have been used to collect patient medical data, enable IoT in cancer monitoring and prediction systems [22]. In addition, [23] it presents a monitoring system for the identification of Covid-19 cases based on Cloud IoT. Then, [24] provides care monitoring and disease diagnosis services based on Cloud IoT by collecting health attributes such as age, gender, weight, user body mass index, Systolic blood pressure, Diastolic blood pressure, Hemoglobin A1c, Gastrointestinal index, body temperature, calculation of user stress based on ECG patterns / EEG, calculation of respiratory index, user's family history of diseases, user's previous medical history and user's home location, where the data obtained is sent to the cloud server via Wi-Fi directly. So that patients, medical teams and family members can access data, both through the web and mobile applications. 


\section{EXPERIMENTAL DESIGN TOOLS}

In this research, the development of an Androidbased health monitoring system uses several methods. The method used in data collection is to attach the patient's health subject. In this case, the intended health subjects are body temperature, blood pressure, heart rate, and oxygen levels in the blood. A set of signals of the patient's health subject can be obtained by adopting many interconnected sensors to observe the patient's health condition. Data regarding the patient's health condition will be collected from sensors and then processed by sending data to the cloud server for later display. This method has fundamental parts such as network, cloud, and user, which are used to load interface files according to the requirements of the designed system.

\subsection{Hardware Design}

The hardware design uses an Arduino Mega microcontroller. While the patient's health parameters were measured using the MLX90614 sensor as a body temperature sensor, Xgzb 040db $1 \mathrm{R}$ sensor as a blood pressure sensor, MAX 30100 sensor as a heart rate sensor, and blood oxygen levels. In addition, the Electronic Blood Pressure Monitor is a tool to determine the patient's heart rate and blood pressure.

MLX90614 as a body temperature measuring sensor works based on the principle of infrared radiation by utilizing temperature changes from object movement or the presence of an object within the sensor range. Meanwhile, the Xgzb 040db $1 \mathrm{R}$ sensor detects blood pressure and continuously monitors the pressure until it reaches the desired pressure. Then the MAX30100 sensor is designed by utilizing biological tissue such as the nature of hemoglobin, which can absorb light. Thus, this sensor can show the rhythm of the heartbeat that reflects the activity of the heart muscle cells and shows the natural rate of blood flow in the arteries to measure oxygen levels in the body. In addition, a sphygmomanometer, a heart-rate blood pressure meter, is used by attaching it to the wrist to read blood pressure in the body.

The input data regarding measuring health conditions collected by several sensors will be connected to the Arduino Mega. The data that Arduino Mega has processed will be sent to the cloud server in real-time. NodeMCU ESP8266, connected to wifi, is used to transmit data about health conditions in realtime to be displayed on the android application.

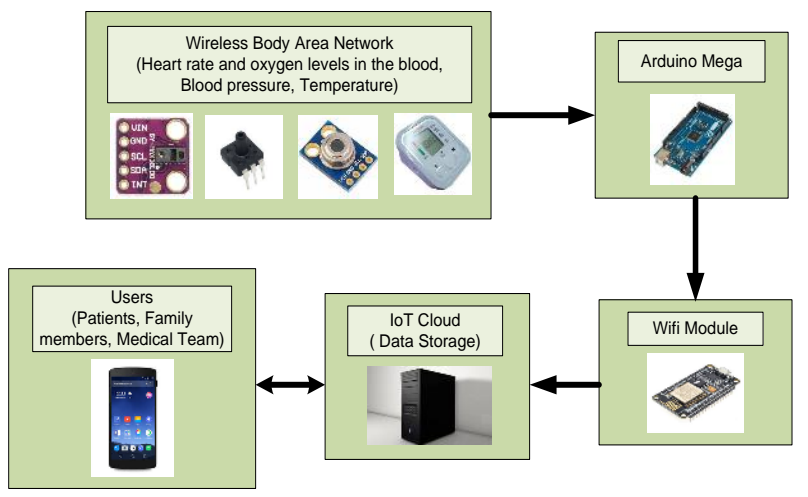

Figure 1. Overall design of the WBAN system

\subsection{Software Design}

The technique on the Android-based health monitoring system shown in Figure 2 uses advances in cloud computing technology. In cloud computing technology, data can be stored and then processed effectively and efficiently in the cloud. Some of the functions implemented in this technology include data storage and processing. As discussed in the previous section, a set of health subject signals can be collected through several interconnected sensors, processed by Arduino Mega, and then forwarded to the cloud to display on an android application.

Then, there are fundamental features to detect body health by displaying information on body temperature, blood pressure, heart rate, and oxygen levels in the blood and providing emergency notifications about body conditions such as health, indications of disease, and need for action. In addition, the process of identifying and diagnosing potential health requires historical data that has been collected. Therefore, a cloud database is created monitoring system to store the data collected by each sensor for each user.

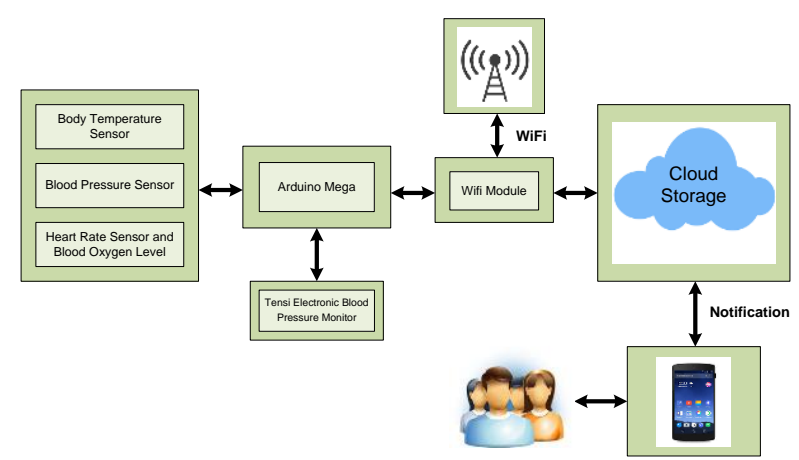

Figure 2. WBAN system architecture 


\section{VISUAL DATA DISPLAY}

The visual data display scheme in the Android-based health monitoring system is applied to provide authority and ease of use for users in accessing health condition data. Health condition data on the android display can identify and provide notifications about health conditions such as sudden heart attacks and high blood pressure, which often endanger a person's health and life. Therefore, this technology was developed to protect a person from these injuries. It is important to monitor, understand, and adequately maintain a person's health condition. Then, abnormal and suspicious health condition data readings from the sensor can be identified appropriately.

Table 1. Adult Health Monitoring Results

\begin{tabular}{|c|c|c|c|c|c|c|c|c|c|}
\hline No & Age & $\begin{array}{c}\text { Body } \\
\text { temperature } \\
\left({ }^{\circ} \mathrm{C}\right)\end{array}$ & $\begin{array}{c}\text { Heart rate } \\
(\mathrm{BPM})\end{array}$ & $\begin{array}{c}\text { Oxygen } \\
\text { levels in } \\
\text { the blood } \\
(\%)\end{array}$ & $\begin{array}{c}\text { Systolic } \\
\text { blood } \\
\text { pressure }\end{array}$ & $\begin{array}{c}\text { distolic } \\
\text { blood } \\
\text { pressure }\end{array}$ & time & $\begin{array}{c}\text { health } \\
\text { status }\end{array}$ & gender \\
\hline 1 & 30 & 36.53 & 74.32 & 95 & 128.25 & 70.79 & $09: 10$ & healthy & $\mathrm{M}$ \\
\hline 2 & 26 & 36.56 & 72.19 & 95 & 127.91 & 67.10 & $09: 15$ & healthy & $\mathrm{P}$ \\
\hline 3 & 32 & 36.51 & 72.21 & 95 & 125.63 & 71.06 & $09: 20$ & healthy & $\mathrm{P}$ \\
\hline 4 & 42 & 36.52 & 43.84 & 96 & 137.24 & 86.59 & 09255 & indication & $\mathrm{P}$ \\
\hline 5 & 37 & 36.75 & 70.43 & 95 & 131.02 & 69.05 & $09: 30$ & healthy & $\mathrm{P}$ \\
\hline 6 & 33 & 36.78 & 70.13 & 95 & 129.64 & 70.28 & $09: 35$ & healthy & $\mathrm{M}$ \\
\hline 7 & 35 & 36.46 & 77.67 & 95 & 119.54 & 76.19 & $09: 40$ & healthy & $\mathrm{P}$ \\
\hline 8 & 26 & 38.75 & 50.64 & 95 & 129.89 & 83.54 & $09: 45$ & indication & $\mathrm{M}$ \\
\hline 9 & 31 & 38.02 & 70.99 & 95 & 142.49 & 91.11 & $09: 50$ & indication & $\mathrm{P}$ \\
\hline 10 & 28 & 36.60 & 68.04 & 95 & 120.05 & 75.57 & $09: 55$ & healthy & $\mathrm{P}$ \\
\hline 11 & 35 & 36.53 & 74.32 & 95 & 128.25 & 68.00 & $09: 10$ & healthy & $\mathrm{M}$ \\
\hline 12 & 31 & 36.56 & 72.19 & 95 & 127.91 & 67.10 & 09115 & healthy & $\mathrm{P}$ \\
\hline 13 & 37 & 36.51 & 72.21 & 95 & 125.63 & 69.06 & $09: 20$ & healthy & $\mathrm{P}$ \\
\hline 14 & 45 & 36.52 & 43.84 & 96 & 137.24 & 86.59 & $09: 25$ & indication & $\mathrm{P}$ \\
\hline 15 & 42 & 36.75 & 70.43 & 95 & 128.02 & 69.05 & $09: 30$ & healthy & $\mathrm{P}$ \\
\hline 16 & 38 & 36.78 & 70.13 & 95 & 129.64 & 70.28 & $09: 35$ & healthy & $\mathrm{M}$ \\
\hline 17 & 42 & 36.46 & 77.67 & 95 & 119.54 & 76.19 & $09: 40$ & healthy & $\mathrm{P}$ \\
\hline 18 & 32 & 38.75 & 50.64 & 95 & 129.89 & 83.54 & $09: 45$ & indication & $\mathrm{M}$ \\
\hline 19 & 36 & 38.02 & 70.99 & 95 & 137.49 & 82.11 & $09: 50$ & indication & $\mathrm{P}$ \\
\hline 20 & 33 & 36.60 & 60.04 & 95 & 119.05 & 74.57 & $09: 55$ & indication & $\mathrm{P}$ \\
\hline
\end{tabular}

Table 2. Elderly Health Monitoring Results

\begin{tabular}{|c|c|c|c|c|c|c|c|c|c|}
\hline No & Age & $\begin{array}{c}\text { Body } \\
\text { temperature } \\
\left({ }^{\circ} \mathrm{C}\right)\end{array}$ & $\begin{array}{l}\text { Heart rate } \\
\text { (BPM) }\end{array}$ & $\begin{array}{c}\text { Oxygen } \\
\text { levels in } \\
\text { the blood } \\
(\%)\end{array}$ & $\begin{array}{l}\text { Systolic } \\
\text { blood } \\
\text { pressure }\end{array}$ & $\mid \begin{array}{c}\text { distolic } \\
\text { blood } \\
\text { pressure }\end{array}$ & time & $\begin{array}{l}\text { health } \\
\text { status }\end{array}$ & gender \\
\hline 1 & 60 & 36.73 & 75.32 & 96 & 130.25 & 71.34 & $12: 10$ & healthy & $\mathrm{W}$ \\
\hline 2 & 63 & 36.66 & 77.19 & 95 & 129.91 & 69.10 & $12: 15$ & healthy & W \\
\hline 3 & 66 & 36.89 & 72.21 & 96 & 127.63 & 70.96 & $12: 21$ & healthy & $\mathrm{W}$ \\
\hline 4 & 76 & 36.77 & 53.84 & 97 & 137.78 & 90.99 & $12: 26$ & indication & W \\
\hline 5 & 68 & 36.70 & 78.43 & 96 & 143.92 & 100.15 & $12: 22$ & need action & $M$ \\
\hline 6 & 69 & 36.69 & 81.13 & 95 & 129.84 & 71.28 & $12: 30$ & \begin{tabular}{|l|} 
healthy \\
\end{tabular} & W \\
\hline 7 & 65 & 36.66 & 79.67 & 96 & 131.46 & 86.49 & $12: 35$ & indication & W \\
\hline 8 & 64 & 37.80 & 55.64 & 95 & 129.99 & 85.89 & $12: 39$ & indication & $\mathrm{W}$ \\
\hline 9 & 80 & 37.88 & 78.99 & 95 & 143.59 & $\begin{array}{l}92.67 \\
\end{array}$ & $12: 43$ & need action & $\mathrm{W}$ \\
\hline 10 & 63 & 36.69 & 66.10 & 95 & 121.05 & 75.97 & \begin{tabular}{|l|l|}
$12: 50$ \\
\end{tabular} & healthy & $\mathrm{W}$ \\
\hline 11 & 62 & 36.69 & 76.56 & 96 & 130.25 & 85.34 & $12: 55$ & indication & $\mathrm{W}$ \\
\hline 12 & 64 & 36.71 & 78.27 & 95 & 127.91 & 70.00 & 13:00 & healthy & W \\
\hline 13 & 65 & 36.91 & 71.21 & 96 & 125.73 & 70.76 & 13:05 & healthy & W \\
\hline 14 & 74 & 36.82 & 54.74 & 97 & 135.67 & 90.33 & 13:10 & indication & W \\
\hline 15 & 65 & 36.76 & 79.52 & 96 & 140.92 & 100.15 & $13: 15$ & indication & $M$ \\
\hline 16 & 67 & 36.75 & 82.26 & 95 & 120.84 & 82.87 & 13:20 & \begin{tabular}{|l} 
healthy \\
\end{tabular} & $\mathrm{W}$ \\
\hline 17 & 63 & 36.69 & 80.67 & 96 & 129.46 & 86.74 & $13: 25$ & indication & W \\
\hline 18 & 65 & 37.87 & 57.52 & 95 & 128.99 & 85.50 & $13: 30$ & \begin{tabular}{|l} 
indication \\
\end{tabular} & $\mathrm{M}$ \\
\hline 19 & 82 & 37.91 & 78.00 & 95 & 143.59 & \begin{tabular}{|l|}
92.00 \\
\end{tabular} & 13:33 & need action & W \\
\hline 20 & 64 & 36.72 & 80.98 & 95 & 121.05 & 75.97 & $13: 40$ & indication & W \\
\hline
\end{tabular}

Tabel 3. Adolescent Health Monitoring Results

\begin{tabular}{|c|c|c|c|c|c|c|c|c|c|}
\hline No & Age & $\begin{array}{c}\text { Body } \\
\text { temperature } \\
\left({ }^{\circ} \mathrm{C}\right)\end{array}$ & $\begin{array}{c}\text { Heart rate } \\
(\mathrm{BPM})\end{array}$ & $\begin{array}{c}\text { Oxygen } \\
\text { levels in } \\
\text { the blood } \\
(\%)\end{array}$ & $\begin{array}{c}\text { Systolic } \\
\text { blood } \\
\text { pressure }\end{array}$ & $\begin{array}{c}\text { distolic } \\
\text { blood } \\
\text { pressure }\end{array}$ & time & $\begin{array}{c}\text { health } \\
\text { status }\end{array}$ & gender \\
\hline 1 & 14 & 36.53 & 74.32 & 96 & 126.25 & 70.79 & $09: 10$ & healthy & W \\
\hline 2 & 19 & 36.56 & 82.19 & 96 & 125.91 & 67.10 & $09: 15$ & healthy & W \\
\hline 3 & 14 & 36.51 & 82.21 & 98 & 125.63 & 71.06 & $09: 21$ & healthy & W \\
\hline 4 & 18 & 36.52 & 68.84 & 96 & 90.24 & 61.59 & $09: 26$ & healthy & W \\
\hline 5 & 12 & 36.75 & 80.43 & 95 & 131.02 & 84.05 & $09: 22$ & healthy & W \\
\hline 6 & 18 & 36.78 & 80.13 & 97 & 122.64 & 66.28 & $09: 30$ & healthy & M \\
\hline 7 & 16 & 36.46 & 77.67 & 95 & 119.54 & 76.19 & $09: 35$ & healthy & $\mathrm{M}$ \\
\hline 8 & 18 & 37.75 & 86.64 & 95 & 90.89 & 73.54 & $09: 39$ & indication & W \\
\hline 9 & 15 & 38.02 & 70.99 & 95 & 96.49 & 75.11 & $09: 43$ & indication & W \\
\hline 10 & 18 & 36.60 & 69.00 & 95 & 120.00 & 75.56 & $09: 50$ & healthy & M \\
\hline 11 & 16 & 36.62 & 76.23 & 96 & 115.25 & 62.59 & $10: 00$ & healthy & W \\
\hline 12 & 17 & 36.64 & 80.56 & 96 & 122.91 & 66.10 & 10.04 & healthy & W \\
\hline 13 & 16 & 36.58 & 79.52 & 98 & 118.63 & 69.06 & $10: 11$ & healthy & W \\
\hline 14 & 16 & 36.55 & 72.34 & 96 & 90.24 & 64.59 & $10: 16$ & healthy & W \\
\hline 15 & 14 & 36.82 & 81.76 & 95 & 94.02 & 67.05 & $10: 22$ & healthy & W \\
\hline 16 & 16 & 36.75 & 80.64 & 97 & 122.64 & 68.28 & $10: 25$ & healthy & M \\
\hline 17 & 18 & 36.52 & 78.55 & 95 & 118.54 & 69.19 & $10: 31$ & healthy & M \\
\hline 18 & 16 & 37.87 & 90.86 & 95 & 92.89 & 74.54 & $10: 37$ & indication & W \\
\hline 19 & 17 & 38.14 & 76.78 & 95 & 90.49 & 77.11 & $10: 42$ & indication & W \\
\hline 20 & 15 & 36.55 & 61.05 & 95 & 120.05 & 76.57 & $10: 45$ & indication & M \\
\hline
\end{tabular}

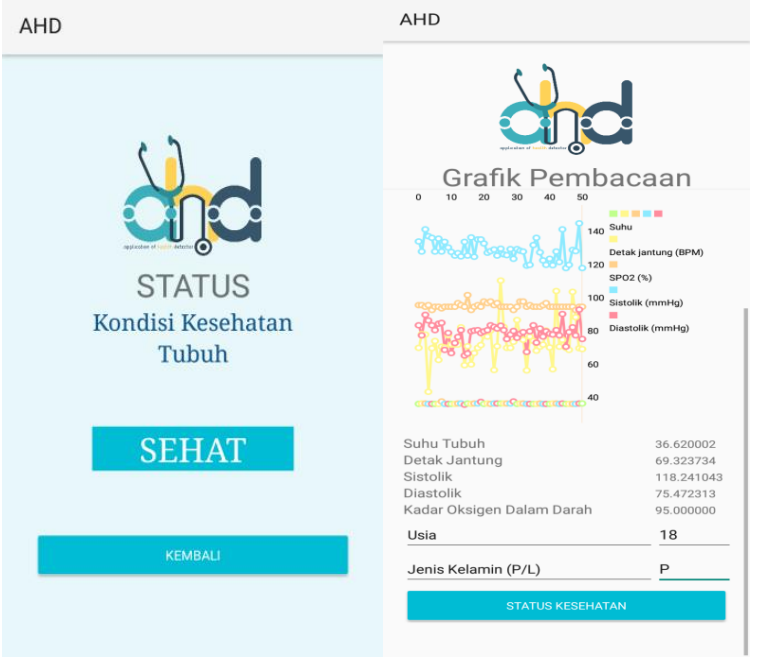

Figure 3. Display of health data visualization on the user's android application

In Figure 3, technology Cloud implementation based on a database storage server implemented. An androidbased mobile application was developed to load an interface file that displays a person's body temperature, blood pressure, heart rate, and blood oxygen levels in real-time. After the power supply is provided, health data regarding body temperature, blood pressure, heart rate, and blood oxygen levels from each measuring sensor will be determined. Each sensor retrieves data containing health information from the patient's body part to be processed by Arduino Mega. Then the same information will be uploaded to the cloud database server to be displayed on the android application page using the NodeMCU ESP8266 connected to Wi-Fi. NodeMCU ESP8266 acts as a medium for sending data to android. Android as the recipient of the data sent by the device to be displayed on the user's mobile application.

Some components in the user's mobile application provide a convenient interface for users to access health data. Authorized users have access to visualize data. User groups are divided into two categories. The first category is patients as monitored subjects. Then, the second category is doctors and nurses as medical officers. All users must be registered in this system through an android-based mobile application, as shown in Figure 5.

This mechanism is critical to implement for users to be able to monitor their health conditions. If abnormal conditions are detected, a warning will be given to the user. The warning is displayed on the user's android application page. 


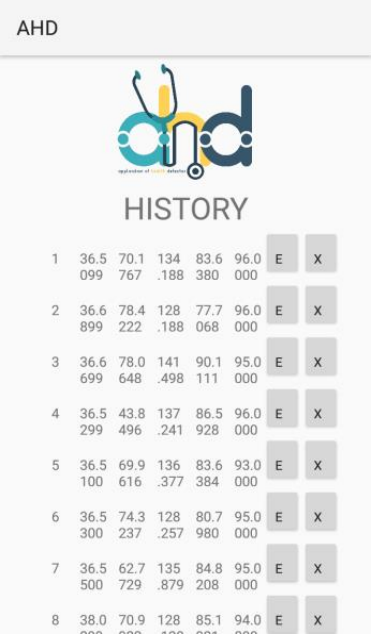

Figure 4. Display of health history data visualization on the android application

In addition, Figure 4 shows the long-term historical data visualized on Android. The image shows the read and stored data of the mechanism adopted to display health data on the patient's body temperature, blood pressure, heart rate, and blood oxygen levels over several weeks

\section{RESULTS AND DISCUSSION}

The results of this Android-based health monitoring system design provide significant benefits and potential in the realm of required health care. The communication modules and wireless body area networks that have been used serve as the primary support. Meanwhile, the patient's health condition can be monitored in real-time. So that emergencies can be recognized accurately and important information regarding related conditions can be immediately informed to users.

The hardware and software design system using a mobile application on Android is intended for patients who need real-time monitoring of health conditions. Health monitored health conditions are body temperature, blood pressure, heart rate, and oxygen levels in a person's blood. With this system, data regarding the patient's health condition can be appropriately stored and displayed online. So that medical professionals can monitor, diagnose, and provide warnings about their patients' health conditions properly at any time.

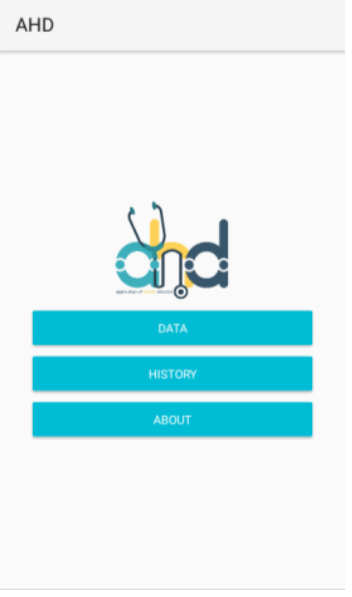

Figure 5. Visualization of the main page on the android application

\section{CONCLUSION}

In designing a health care monitoring system, an android-based monitoring tool was created by utilizing the IoT network and cloud computing to improve the quality of the relationship between the medical team and patients. The system offers regular, efficient online monitoring of patients proposing further improved disease diagnoses even in the absence of a doctor. Monitoring systems can be implemented with sensing elements and wireless modules that must be secured so that health-related information messages are not corrupted.

The Internet of Things plays a role in communicating messaging standards and communication protocols to send important messages related to patient health data securely. Furthermore, the open-source Cloud IoT is effective for storing data from some worn medical sensors. The benefit of digital storage is data retrieval in an easy and faster way in an emergency for safe health.

\section{REFERENCES}

[1] S. V. Zanjal and G. R. Talmale, "Medicine Reminder and Monitoring System for Secure Health Using IOT," Phys. Procedia, vol. 78, no. December 2015, pp. 471-476, 2016, doi: 10.1016/j.procs.2016.02.090.

[2] R. Negra, I. Jemili, and A. Belghith, "Wireless Body Area Networks: Applications and Technologies," Procedia Comput. Sci., vol. 83, pp. 1274-1281, 2016, doi: 10.1016/j.procs.2016.04.266.

[3] R. Srinivasan and E. Kannan, "A review on energy efficient routing protocols in wireless sensor networks," Int. J. Appl. Eng. Res., vol. 10, no. 11, 
pp. 27701-27715, 2015, doi: 10.26634/jwen.4.4.5912.

[4] J. Craig and V. Patterson, "Introduction to the practice of telemedicine," J. Telemed. Telecare, vol. 11, no. 1, pp. 3-9, 2005, doi: $10.1258 / 1357633053430494$.

[5] B. Singh, S. Urooj, S. Mishra, and S. Haldar, "Blood pressure monitoring system using wireless technologies," Procedia Comput. Sci., vol. 152, pp. 267-273, 2019, doi: 10.1016/j.procs.2019.05.017.

[6] I. Almarashdeh et al., "Real-time elderly healthcare monitoring expert system using wireless sensor network," arXiv, 2019, doi: 10.2139/ssrn.3415732.

[7] V. P. Cornet and R. J. Holden, "Systematic review of smartphone-based passive sensing for health and wellbeing," J. Biomed. Inform., vol. 77, no. December 2017, pp. 120-132, 2018, doi: 10.1016/j.jbi.2017.12.008.

[8] K. Elgazzar, M. Aboelfotoh, P. Martin, and H. S. Hassanein, "Ubiquitous health monitoring using mobile web services," Procedia Comput. Sci., vol. 10, pp. 332-339, 2012, doi: 10.1016/j.procs.2012.06.044.

[9] D. Preuveneers, Y. Berbers, and W. Joosen, "The future of mobile e-health application development: Exploring HTML5 for context-aware diabetes monitoring," Procedia Comput. Sci., vol. 21, pp. 351-359, 2013, doi: 10.1016/j.procs.2013.09.046.

[10] S. Harous, M. El Menshawy, M. A. Serhani, and A. Benharref, "Mobile health architecture for obesity management using sensory and social data," Informatics Med. Unlocked, vol. 10, no. December 2017, pp. 27-44, 2018, doi: 10.1016/j.imu.2017.12.005.

[11] J. Wan et al., "Wearable IoT enabled real-time health monitoring system," Eurasip J. Wirel. Commun. Netw., vol. 2018, no. 1, 2018, doi: 10.1186/s13638-018-1308-x.

[12] A. Taqwa et al., "Prototype Development of Heartbeat and Body Temperature Monitoring System Based on Internet of Things," vol. 7, pp. 605-612, 2021.

[13] M. Pravin Savaridass, N. Ikram, R. Deepika, and R. Aarnika, "Development of smart health monitoring system using Internet of Things," Mater. Today Proc., no. xxxx, 2020, doi: 10.1016/j.matpr.2020.03.046.

[14] D. Sunil Kumar, B. Prakash, B. J. Subhash Chandra, P. S. Kadkol, V. Arun, and J. J. Thomas, "An android smartphone-based randomized intervention improves the quality of life in patients with type 2 diabetes in Mysore, Karnataka, India," Diabetes Metab. Syndr. Clin. Res. Rev., vol. 14, no. 5, pp. 1327-1332, 2020, doi: 10.1016/j.dsx.2020.07.025.

[15] N. Noury, B. Perriot, N. Noury, J. Argod, and J. L. Pepin, "Monitoring physical activities of COPD patients with a network of sensors," Irbm, vol. 35, no. 6, pp. 329-333, 2014, doi: 10.1016/j.irbm.2014.03.002.

[16] A. Widhiasi, R. Idrus, M. F. Pasha, and M. Syukur, "A feasibility study scheme of an android-based integrated wearable ECG monitoring system," Procedia Comput. Sci., vol. 21, pp. 407-414, 2013, doi: 10.1016/j.procs.2013.09.053.

[17] T. Aladwani, "Scheduling IoT Healthcare Tasks in Fog Computing Based on their Importance," Procedia Comput. Sci., vol. 163, pp. 560-569, 2019, doi: 10.1016/j.procs.2019.12.138.

[18] P. P. Ray, "A survey of IoT cloud platforms," Futur. Comput. Informatics J., vol. 1, no. 1-2, pp. 35-46, 2016, doi: 10.1016/j.fcij.2017.02.001.

[19] A. Flammini and E. Sisinni, "Wireless sensor networking in the internet of things and cloud computing era," Procedia Eng., vol. 87, pp. 672 679, 2014, doi: 10.1016/j.proeng.2014.11.577.

[20] P. M. Kumar, S. Lokesh, R. Varatharajan, G. Chandra Babu, and P. Parthasarathy, "Cloud and IoT based disease prediction and diagnosis system for healthcare using Fuzzy neural classifier," Futur. Gener. Comput. Syst., vol. 86, pp. 527-534, 2018, doi: 10.1016/j.future.2018.04.036.

[21] Z. Yang, Q. Zhou, L. Lei, K. Zheng, and W. Xiang, "An IoT-cloud Based Wearable ECG Monitoring System for Smart Healthcare," J. Med. Syst., vol. 40, no. 12, 2016, doi: 10.1007/s10916-016-0644-9.

[22] M. Anuradha et al., "IoT enabled cancer prediction system to enhance the authentication and security using cloud computing," Microprocess. Microsyst., vol. 80, p. 103301, 2021, doi: 10.1016/j.micpro.2020.103301.

[23] M. Otoom, N. Otoum, M. A. Alzubaidi, Y. Etoom, and R. Banihani, "An IoT-based framework for early identification and monitoring of COVID-19 cases," Biomed. Signal Process. Control, vol. 62, no. April, p. 102149, 2020, doi: 10.1016/j.bspc.2020.102149.

[24] P. Verma and S. K. Sood, "Cloud-centric IoT based disease diagnosis healthcare framework," J. Parallel Distrib. Comput., vol. 116, pp. 27-38, 2018, doi: 10.1016/j.jpdc.2017.11.018. 